\title{
Inducible nitric oxide synthase is an endogenous neuroprotectant after traumatic brain injury in rats and mice
}

\author{
Elizabeth H. Sinz, ${ }^{1,2}$ Patrick M. Kochanek, ${ }^{1,2,3,4}$ C. Edward Dixon, ${ }^{2,4,5}$ \\ Robert S.B. Clark, ${ }^{1,2,3,4}$ Joseph A. Carcillo, ${ }^{1,3}$ Joanne K. Schiding, ${ }^{1,2}$ Minzhi Chen, ${ }^{1}$ \\ Stephen R. Wisniewski, ${ }^{6}$ Timothy M. Carlos, ${ }^{7}$ Debra Williams, ${ }^{8}$ Steven T. DeKosky, ${ }^{4,9}$ \\ Simon C. Watkins, ${ }^{10}$ Donald W. Marion, ${ }^{2,4,5}$ and Timothy R. Billiar ${ }^{8}$ \\ ${ }^{1}$ Department of Anesthesiology and Critical Care Medicine, \\ ${ }^{2}$ Safar Center for Resuscitation Research, \\ ${ }^{3}$ Department of Pediatrics, \\ ${ }^{4}$ Brain Trauma Research Center, \\ ${ }^{5}$ Department of Neurological Surgery, \\ ${ }^{6}$ Department of Epidemiology and Public Health, \\ ${ }^{7}$ Department of Medicine, \\ ${ }^{8}$ Department of Surgery, \\ ${ }^{9}$ Department of Psychiatry, and \\ ${ }^{10}$ Department of Cell Biology and Physiology, University of Pittsburgh, Pittsburgh, Pennsylvania 15260 USA \\ Address correspondence to: Patrick M. Kochanek, Safar Center for Resuscitation Research, 3434 Fifth Avenue, \\ 201 Hill Building, Pittsburgh, Pennsylvania 15260, USA. Phone: (412) 383-1900; Fax: (412) 624-0943; \\ E-mail: kochanek@smtp.anes.upmc.edu. \\ Received for publication March 1, 1999, and accepted in revised form July 29, 1999.
}

\begin{abstract}
Nitric oxide (NO) derived from the inducible isoform of NO synthase (iNOS) is an inflammatory product implicated both in secondary damage and in recovery from brain injury. To address the role of iNOS in experimental traumatic brain injury (TBI), we used 2 paradigms in 2 species. In a model of controlled cortical impact (CCI) with secondary hypoxemia, rats were treated with vehicle or with 1 of 2 iNOS inhibitors (aminoguanidine and $\mathrm{L}-\mathrm{N}$-iminoethyl-lysine), administered by Alzet pump for 5 days and 1.5 days after injury, respectively. In a model of CCI, knockout mice lacking the iNOS gene ( $\mathrm{iNOS}^{-/}$) were compared with wild-type $\left(\mathrm{iNOS}^{+/+}\right)$mice. Functional outcome (motor and cognitive) during the first 20 days after injury, and histopathology at 21 days, were assessed in both studies. Treatment of rats with either of the iNOS inhibitors after TBI significantly exacerbated deficits in cognitive performance, as assessed by Morris water maze (MWM) and increased neuron loss in vulnerable regions (CA3 and CA1) of hippocampus. Uninjured $i \mathrm{NOS}^{+/+}$and $i \mathrm{NOS}^{-/-}$mice performed equally well in both motor and cognitive tasks. However, after TBI, $\mathrm{iNOS}^{-/-}$mice showed markedly worse performance in the MWM task than $i \mathrm{NOS}^{+/+}$mice. A beneficial role for iNOS in TBI is supported.
\end{abstract}

J. Clin. Invest. 104:647-656 (1999).

\section{Introduction}

In some diseases of the central nervous system (CNS), such as meningitis, Alzheimer's disease, multiple sclerosis, and stroke, the local inflammatory response contributes to neurologic damage (1-3). Prevailing wisdom has been that secondary damage from ischemia and traumatic brain injury (TBI) is partly due to inflammatory mediators $(4,5)$. However, the inflammatory response could also facilitate neurologic recovery (6). Several proinflammatory mediators (e.g., TNF- $\alpha$, IL-1 $\beta$, NF-KB) exhibit neuroprotective properties $(7-10)$. Thus, the endogenous inflammatory response may exacerbate secondary injury, improve neurologic recovery, or both.

Nitric oxide (NO) is an inflammatory product that is implicated both in secondary damage (11) and in neurologic recovery (12). The location (13), timing (14-16), and amount of NO production (17) may determine its role, as may the type of insult (18). NO produced by endothelial NO synthase (eNOS) provides benefit in models of TBI and focal cerebral ischemia by augmenting penumbral blood flow $(19,20)$. This benefit prompted a recent trial of $\mathrm{L}$-arginine in human TBI (C. Robertson, personal communication). In contrast, $\mathrm{NO}$ produced by neuronal NO synthase (nNOS) contributes to neuron damage after ischemic or excitotoxic insult (21-23). eNOS and nNOS are isoforms of constitutive NO synthase that are regulated by calcium and are responsible for intermittent production of small amounts of $\mathrm{NO}(24)$.

Inducible NO synthase (iNOS) is neither calcium-regulated nor detectable in normal brain. It is induced by a variety of inflammatory stimuli such as cytokines. Gene expression of iNOS requires activation of the 
a
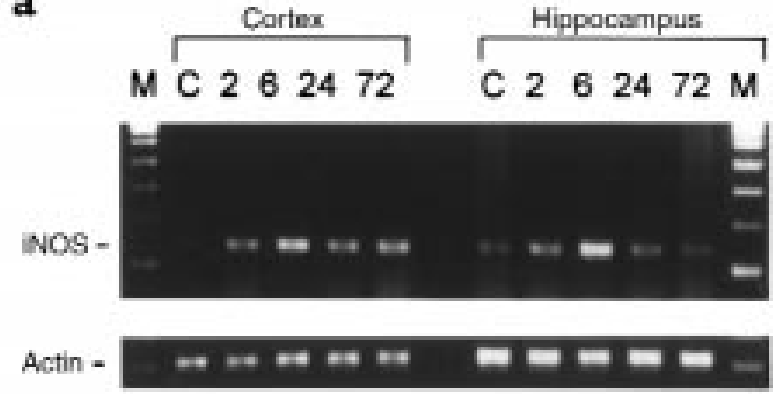

b

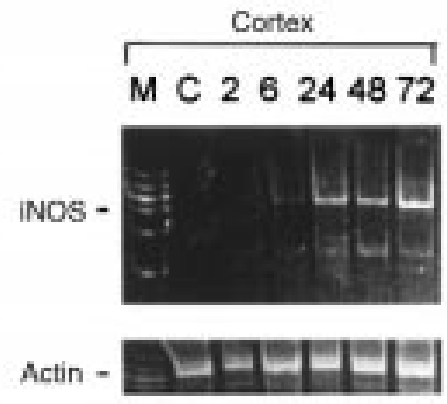

Figure 1

iNOS mRNA expression in rats and mice after TBI. iNOS mRNA was detected using RT-PCR. (a) In rats, iNOS mRNA was increased in injured cortex at 2, 6, 24, and 72 hours, and in ipsilateral hippocampus at 2 and 6 hours after TBI plus secondary hypoxemic insult, compared with control ( $n=2$ animals per group). A 138-bp PCR product is seen. (b) In C57BL/6J mice, iNOS mRNA was increased in injured cortex at 24, 48, and 72 hours after TBI, compared with control $(n=$ 3 animals per group). A 429-bp PCR product is seen. RT-PCR for actin confirmed equal loading of RNA. M, marker; $C$, uninjured control.

transcriptional factor NF-KB $(24,25)$. Typically, iNOS is not found in brain until 6-12 hours after TBI (26). Upregulation of iNOS in rat hippocampus has been reported after fluid percussion (FP) TBI (27). Once expressed, iNOS produces large amounts of NO for sustained periods, limited only by substrate and cofactor availability. After experimental focal cerebral ischemia, and in FP-TBI within 96 hours, iNOS-derived $\mathrm{NO}$ is acutely detrimental (28), possibly because of toxic effects of $\mathrm{NO}$ metabolites such as peroxynitrite. Infarct size is decreased after cerebral ischemia by the iNOS inhibitor aminoguanidine $(A G)(29,30)$. Iadecola et al. (15) confirmed this finding, showing a reduction in infarct volume after focal ischemia in $\mathrm{NNOS}^{-/-}$ mice compared with wild-type mice.

In contrast, AG exacerbates brain injury associated with lymphocytic choriomeningitis in mice (18), and $\mathrm{iNOS}^{-1-}$ mice develop more severe experimental allergic encephalitis (EAE) than do wild-type mice $(31,32)$, indicating a protective role for iNOS in models of CNS infection and immune-mediated damage. Unlike focal cerebral ischemia, in EAE symptoms develop slowly, leading to neurologic impairment after 21-25 days (31).

We sought to determine the effects of iNOS on functional and neuropathologic outcome after TBI using 2 models: a rat model using treatment with the iNOS inhibitors AG or L- $N$-iminoethyl-lysine (L-NIL), and assessment of TBI in $i \mathrm{NOS}^{-1-}$ mice.

\section{Methods}

The University of Pittsburgh Animal Care and Use Committee approved all of the experiments in this report.

Rat model of TBI. A previously described rat model of controlled cortical impact (CCI) with a secondary hypoxemic insult was used (33-35). In adult male Sprague-Dawley rats, anesthesia was induced with $4 \%$ isoflurane (Anaquest Inc., Memphis, Tennessee, USA) in $\mathrm{O}_{2}$. The trachea was intubated with a 14-gauge angiocatheter, and the lungs were mechanically ventilated with $2 \%$ isoflurane in $\mathrm{N}_{2} \mathrm{O}(66 \%)$ and $\mathrm{O}_{2}(32 \%)$. A femoral arterial catheter was inserted for blood sampling, monitoring mean arterial blood pressure (MABP), and administration of pancuronium bromide $(0.1 \mathrm{mg} / \mathrm{kg}$; Elkins-Sinn, Cherry Hill, New Jersey, USA). A rectal probe was inserted to monitor temperature. Before injury, an arterial blood sample was obtained, and $\mathrm{pH}$, blood gases, hematocrit, and blood glucose were measured. To simulate the clinical setting of TBI, secondary insult, and resuscitation, we used the following protocol (33). A craniotomy was made over the left parietal cortex. A probe was inserted through a burr hole in the left parietal cortex to monitor brain temperature. Rats were then warmed to a brain temperature of $37.0 \pm 0.5^{\circ} \mathrm{C}$ and allowed to equilibrate under anesthesia ( $1.1 \%$ isoflurane, and $\left.\mathrm{N}_{2} \mathrm{O} / \mathrm{O}_{2}, 2: 1\right)$ for 30 minutes. After removal of the bone flap, injury was produced using the CCI device $(34,35)$. A penetration depth of $2.5 \mathrm{~mm}$ and a velocity of $4 \mathrm{~m} / \mathrm{s}$ were target insult parameters. Impact velocity was measured (35). To produce moderate hypoxemia, $\mathrm{N}_{2} \mathrm{O}$, air, and $\mathrm{O}_{2}$ were blended to achieve an $\mathrm{FiO}_{2}$ of $11 \%$, beginning 1 minute after $\mathrm{CCI}(33)$. In prior studies, this produced $\mathrm{a}_{\mathrm{PaO}}$ in rats of approximately $44 \mathrm{mmHg}(33,36)$. Arterial blood gas tensions, MABP, and blood glucose were measured at 25 minutes after trauma. The bone flap was replaced and sealed with dental cement (Vernon Benshoff Co., Albany, New York, USA), and the scalp incision was closed. Hypoxemia was maintained for 30 minutes; then $\mathrm{FiO}_{2}$ was increased to $100 \%$, and Alzet pumps (Alza Corp., Palo Alto, California, USA) preloaded with iNOS inhibitor or saline vehicle were inserted (see protocol below). Once recovered from anesthesia, rats were extubated and then observed in $100 \% \mathrm{O}_{2}$ for $30 \mathrm{~min}$ utes before being returned to their cages.

Mouse model of TBI. A previously described mouse model of CCI was used $(37,38)$. Anesthesia was induced in male mice ( 12 weeks old) with $4 \%$ isoflurane in $\mathrm{O}_{2}$. Mice were positioned in a stereotaxic frame, spontaneously breathing $2 \%$ isoflurane, $66 \% \mathrm{~N}_{2} \mathrm{O}$, and $32 \% \mathrm{O}_{2}$. A temperature probe was inserted into the left frontal cortex. A craniotomy was made over the left parietal cortex. Isoflurane was then reduced to $1 \%$. Once a brain temperature of $37.0 \pm 0.5^{\circ} \mathrm{C}$ was reached, it was maintained at that level for 5 minutes before a vertically 
Table 1

Controlled and observed physiologic variables in rats

\begin{tabular}{|c|c|c|c|c|}
\hline \multirow[t]{2}{*}{ Parameter } & \multicolumn{4}{|c|}{ Treatment group } \\
\hline & Vehicle & AG & L-NIL & Sham \\
\hline \multicolumn{5}{|l|}{ Before injury } \\
\hline Body weight (g) & $345 \pm 5$ & $346 \pm 7$ & $351 \pm 7$ & $357 \pm 12$ \\
\hline Blood pH & $7.38 \pm 0.01$ & $7.38 \pm 0.01$ & $7.39 \pm 0.01$ & $7.37 \pm 0.0$ \\
\hline $\mathrm{PaCO}_{2}(\mathrm{mmHg})$ & $40.0 \pm 1.1$ & $40.8 \pm 1.3$ & $37.5 \pm 1.6$ & $39.8 \pm 2.0$ \\
\hline $\mathrm{PaO}_{2}(\mathrm{mmHg})$ & $173 \pm 4$ & $160 \pm 5$ & $142 \pm 7^{A}$ & $158 \pm 7$ \\
\hline $\operatorname{MABP}(\mathrm{mmHg})$ & $118 \pm 10$ & $110 \pm 5$ & $108 \pm 5$ & $105 \pm 6$ \\
\hline Brain temperature $\left({ }^{\circ} \mathrm{C}\right)$ & $37.0 \pm 0.5$ & $37.1 \pm 0.3$ & $37.0 \pm 0.5$ & $37.0 \pm 0.6$ \\
\hline Hematocrit (\%) & $34.2 \pm 1.2$ & $35.9 \pm 0.9$ & $36.7 \pm 1.4$ & $33.5 \pm 1.8$ \\
\hline Blood glucose $(\mathrm{mg} / \mathrm{dL})$ & $212 \pm 17$ & $199 \pm 17$ & $211 \pm 19$ & $171 \pm 30$ \\
\hline \multicolumn{5}{|l|}{ After injury (25 min) } \\
\hline Blood pH & $7.40 \pm 0.01$ & $7.38 \pm 0.01$ & $7.38 \pm 0.01$ & $7.37 \pm 0.0$ \\
\hline $\mathrm{PaCO}_{2}(\mathrm{mmHg})$ & $38.9 \pm 2.0$ & $39.4 \pm 1.9$ & $40.1 \pm 1.1$ & $42.2 \pm 1.5$ \\
\hline $\mathrm{PaO}_{2}(\mathrm{mmHg})$ & $46 \pm 1$ & $44 \pm 1$ & $41 \pm 1$ & $128 \pm 28^{B}$ \\
\hline $\mathrm{MABP}(\mathrm{mmHg})$ & $64 \pm 4$ & $70 \pm 7$ & $68 \pm 4$ & $96 \pm 11^{B}$ \\
\hline Brain temperature $\left({ }^{\circ} \mathrm{C}\right)$ & $37.1 \pm 0.4$ & $37.0 \pm 0.8$ & $37.1 \pm 0.4$ & $37.1 \pm 0.4$ \\
\hline Blood glucose $(\mathrm{mg} / \mathrm{dL})$ & $237 \pm 18$ & $195 \pm 17$ & $223 \pm 26$ & $218 \pm 59$ \\
\hline
\end{tabular}

Values are mean \pm SEM. ${ }^{A} P<0.05$ vs. vehicle- and AG-treated groups. ${ }^{B} P<0.05$ vs. all other groups subjected to TBI.

directed CCI was delivered, using a 3-mm flat-tipped impounder with a depth of $1.0 \mathrm{~mm}$ and a velocity of 6 $\mathrm{m} / \mathrm{s}$. The bone flap was replaced with dental cement, the scalp was sutured closed, and the anesthetic was discontinued. Mice were observed for 30 minutes in supplemental $\mathrm{O}_{2}$ and then returned to their cages.

iNOS RT-PCR in rats and mice. RT-PCR was performed to determine the temporal expression of iNOS mRNA in brain after TBI. Injured cortex and ipsilateral hippocampus from adult male Sprague-Dawley uninjured rats and rats at 2, 6, 24, and 72 hours after TBI $(n=2$ rats per group) were assayed. Injured cortex from C57BL/6J uninjured mice and mice at 2, 6, 24, 48, and 72 hours after TBI ( $n=3$ mice per group) was assayed. Animals were perfused transcardially with ice-cold saline. Brain regions of interest were dissected and removed, and total RNA was extracted with an RNA isolation kit (Molecular Research Center, Cincinnati, Ohio, USA). Concentration and purity of RNA were determined by measuring absorbance at $260 / 280 \mathrm{~nm}$. Samples were digested with $4 \mathrm{~mL}$ of DNase I and $0.5 \mathrm{~mL}$ of RNase inhibitor (Promega Corp., Madison, Wisconsin, USA) in buffer containing $40 \mathrm{mM}$ Tris ( $\mathrm{pH} 7.5$ ), $6 \mathrm{mM} \mathrm{MgCl}_{2}$, and 2 $\mathrm{mM} \mathrm{CaCl}_{2}$. Treated samples were incubated at $37^{\circ} \mathrm{C}$ for 30 minutes. RNA was again extracted.

For RT-PCR, $8 \mu \mathrm{L}$ of sample, $2.5 \mu \mathrm{M}$ of random hexamers, and $20 \mu \mathrm{L}$ of RNase inhibitor were heated to $94^{\circ} \mathrm{C}$ for 2 minutes and cooled on ice for 5 minutes (39). To this mixture, $4 \mu \mathrm{L}$ of $5 \times \mathrm{H}$-reverse transcriptase (H-rt) buffer, DTT (0.01 M), 2 mL dNTP (1 mM), and $20 \mu \mathrm{L}$ of RNase inhibitor were added. The mixture was incubated at $41^{\circ} \mathrm{C}$ for 15 minutes, and $2 \mu \mathrm{L}(200$ $\mathrm{U} / \mu \mathrm{L}$ ) of Superscript RNase H-rt enzyme (GIBCO BRL, Baltimore, Maryland, USA) was added. This mixture was incubated for 60 minutes at $41^{\circ} \mathrm{C}$, heated to $99^{\circ} \mathrm{C}$ for 5 minutes to inactivate the H-RT enzyme, and cooled to $4^{\circ} \mathrm{C}$.

PCR amplification of CDNA was performed with the following primers: rat iNOS forward primer 5'-CATTCAGATCCCGAAACGTAC-3'; rat iNOS reverse primer 5'-AGCCTCATGGTGAACACGTTCT-3'; rat actin forward primer $5^{\prime}$-TGAGAGGGAAATCGTGCGT-3'; rat actin reverse primer 5'-TCATGGATGCCACAGGATTCC-3'; mouse iNOS forward primer 5'-ATGACCAGTATAAGGCAAGC3'; mouse iNOS reverse primer 5'-GCTCTGGATGAGCCTATATTG-3'; mouse actin forward primer $5^{\prime}$-TTCTACAATGAGCTGCGTGTG-3'; and mouse actin reverse primer $5^{\prime}$-CACTGTGTTGGCATAGAGGTC-3'. For cDNA from rat samples, the following were added to yield a final reaction volume of $100 \mu \mathrm{L}: 1 \mu \mathrm{L}$ of the cDNA product; $10 \mu \mathrm{L}$ PCR buffer (50 $\mathrm{mM} \mathrm{KCl}$ and $10 \mathrm{mM}$ Tris-HCl, $\mathrm{pH}$ 8.3); 4 $\mathrm{mM} \mathrm{MgCl} 2 ; 0.2 \mathrm{mM}$ each of dATP, dCTP, dGTP, and dTTP; $1 \mu \mathrm{L}$ forward primer; 1 $\mu \mathrm{L}$ reverse primer; $10 \mu \mathrm{L}$ DMSO; and water. The mixture was overlaid with mineral oil and heated at $94^{\circ} \mathrm{C}$ for 5 minutes before the addition of $2.5 \mathrm{U}$ of AmpliTaq DNA polymerase (Perkin-Elmer Applied Biosystems, Foster City, California, USA). Rat iNOS cDNA was amplified at $94^{\circ} \mathrm{C}$ for 1 minute, $60^{\circ} \mathrm{C}$ for 1 minute, and $72^{\circ} \mathrm{C}$ for 3 minutes, for 40 cycles. Rat actin cDNA was amplified at $94^{\circ} \mathrm{C}$ for 1 minute, $57^{\circ} \mathrm{C}$ for 1 minute, and $72^{\circ} \mathrm{C}$ for 3 minutes, for 40 cycles. For cDNA from mouse samples, the following were added to give a final reaction volume of $100 \mu \mathrm{L}: 1 \mu \mathrm{L}$ of the cDNA product; $10 \mu \mathrm{L}$ PCR buffer $\left[75 \mathrm{mM}\left(\mathrm{NH}_{4}\right)_{2} \mathrm{SO}_{4}, 300 \mathrm{mM}\right.$ Tris$\mathrm{HCl}(\mathrm{pH} 8.5)] ; 2.5 \mathrm{mM} \mathrm{MgCl}_{2} ; 0.1 \mathrm{mM}$ each of dATP, $\mathrm{dCTP}, \mathrm{dGTP}$, and dTTP; $1 \mu \mathrm{L}$ forward primer; $1 \mu \mathrm{L}$ reverse primer; and water. The mixture was overlaid with mineral oil and heated at $94^{\circ} \mathrm{C}$ for 5 minutes before $1 \mathrm{U}$ of Taq DNA polymerase (Perkin-Elmer Applied Biosystems) was added. Mouse iNOS cDNA and actin cDNA were amplified at $94^{\circ} \mathrm{C}$ for 1 minute, $57^{\circ} \mathrm{C}$ for 2 minutes, and $72^{\circ} \mathrm{C}$ for 3 minutes, for 30 cycles. RT-PCR products were separated on $8 \%$ acrylamide gels, stained with ethidium bromide, and photographed. Controls included samples run without RNA and reverse transcription.

PCR of mouse genomic DNA. PCR was performed on brain genomic DNA from $i \mathrm{NOS}^{-/-}$and $i \mathrm{NOS}^{+/+}$mice. DNA was extracted using the Wizard Genomic DNA purification system (Promega Corp.). DNA was quantified, and $200 \mathrm{ng}$ was used in each reaction. The choice of primers for amplification of murine iNOS DNA were as follows: a $5^{\prime}$ primer flanking the iNOS2 gene (5'ATCAGCCTTTCTCTGTCTCC-3'), a $3^{\prime}$ primer specific for the wild-type allele (5'-GGCTTTCTGTCTGTTCTCTC-3'), and a $3^{\prime}$ primer specific for the 
mutant allele (5'-GCCTGAAGAACGAGATCAGCAGCCTCTG-3'). PCR conditions were as follows: 1 cycle at $96^{\circ} \mathrm{C}$ for 3 minutes; 30 cycles at $94^{\circ} \mathrm{C}$ for 30 seconds, $65^{\circ} \mathrm{C}$ for 45 seconds, and $72^{\circ} \mathrm{C}$ for 3 minutes; and 1 cycle at $72^{\circ} \mathrm{C}$ for 7 minutes, using a DNA Thermal Cycler (model 480; Perkin-Elmer Applied Biosystems). Known $i \mathrm{NOS}^{+/+}$and $i \mathrm{NOS}^{-/-}$mouse DNA (identified previously by Southern blot) served as positive controls. An aliquot $(25 \mu \mathrm{L})$ of the PCR reaction product was stained and viewed on a $2 \%$ agarose gel.

Assessment of motor performance. Gross vestibulomotor function was assessed using a beam-balance task (40). This task consisted of placing a rat on a suspended, narrow wooden beam ( $1.5 \mathrm{~cm}$ wide) and measuring the latency (up to 60 seconds) that it remained on the beam. Training consisted of 3 trials, which served as baseline. Finer components of vestibulomotor function and coordination were assessed in rats by a blinded observer, using a beam-walking task (41). Two days before injury, rats were trained to escape a bright light and loud white noise by traversing a narrow wooden beam $(2.5 \times 100 \mathrm{~cm})$ to enter a darkened goal box at the opposite end of the beam. Rats were placed at one end of the beam close to the source of light and noise. The noise and light were terminated when the rat entered the goal box. Performance was assessed by measuring the rat's latency to traverse the beam (mean of 3 trials).

In mice, vestibulomotor function was assessed using a wire-grip test (42). Mice were placed on a metal wire $40 \mathrm{~cm}$ long, suspended $40 \mathrm{~cm}$ above a foam mat between 2 vertical bars. Mice were introduced to the wire so that both front paws came in contact with the wire and there was an equal chance at grasping the wire. Mice were allowed to either fall to the pad, remain hanging on the wire, or crawl along the wire to one of the supporting poles. The latency that a mouse remained on the wire within a 30 -second interval was measured. Grip-test score was also quantified using a 5-point scale (42). Motor performance during Morris water maze (MWM) testing was assessed in both rats and mice by measuring swim speed with a video tracking system.

Spatial memory performance assessments. A spatial memory acquisition paradigm of the MWM was used for cognitive assessment. The MWM for rats used a circular pool $180 \mathrm{~cm}$ in diameter and $60 \mathrm{~cm}$ high, filled with water to a depth of $28 \mathrm{~cm}$. A Plexiglas platform 10 $\mathrm{cm}$ in diameter and $26 \mathrm{~cm}$ high (i.e., $2 \mathrm{~cm}$ below the water's surface) was used as a hidden goal platform. The water maze for mice used a pool $85 \mathrm{~cm}$ in diameter and $61 \mathrm{~cm}$ high, filled with water to a depth of 28 $\mathrm{cm}$. A hidden platform $8.6 \mathrm{~cm}$ in diameter and $27 \mathrm{~cm}$ high was used. Each pool was located in a room with numerous extramaze cues (shapes on the walls) that remained constant during the studies. Water was kept at $20-22^{\circ} \mathrm{C}$. A video tracking system (San Diego Instruments Inc., San Diego, California, USA) was used to record and quantify the swimming motions of the animals. The tracking system consisted of a charge-coupled device interfaced to a personal computer. The hidden-platform version of the MWM was used to assess an animal's ability to learn spatial relations between distal cues and the escape platform. Performance of this task is impaired by lesions to the hippocampus and cortex. Four daily trials over 7 days were used. A blinded observer placed each animal in the pool facing the wall. Animals began a trial from each of the 4 possible start locations in random order. Platform location was kept constant for each animal. Animals were given up to 120 seconds to find the hidden platform. If an animal failed to find the platform, it was placed on the platform. Animals were allowed to remain on the platform for 30 seconds before being placed in a heated incubator between trials (4-minute intertrial interval). Testing on the final 2 days consisted of a visible-platform task in which the platform was raised to $2 \mathrm{~cm}$ above the water surface. (The visibleplatform task tests for potential nonspecific deficits in visual and motor function.) Motor testing was done on each of the first 5 days after TBI. Spatial memory was tested beginning at 14 days after TBI.

Assessment of neuropathology. At 21 days after TBI, rats or mice were anesthetized and perfused with $500 \mathrm{~mL}$ or $100 \mathrm{~mL}$ of $2 \%$ paraformaldehyde, respectively. Brains were removed and stored in $2 \%$ paraformaldehyde. Coronal frozen sections $(10 \mu \mathrm{m})$ were prepared through the entire brain at $1-\mathrm{mm}$ (rats) or $0.5-\mathrm{mm}$ (mice) intervals from the occiput; in rats, sections were also taken through the lesion center $(\sim 2.6 \mathrm{~mm}$ posterior to bregma) for hippocampal neuron counts. Sections were stained with cresyl violet. In the serial sections, the margins of both the contusion and the total

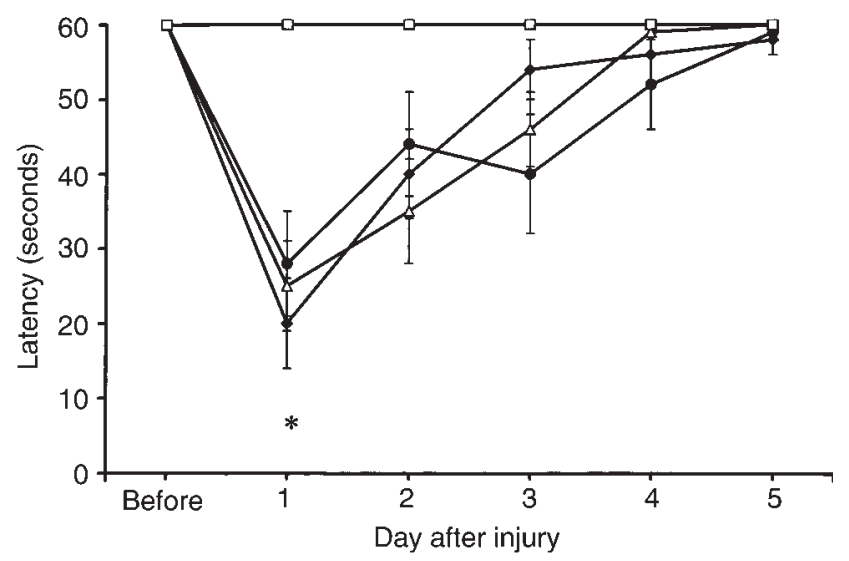

Figure 2

Mean latencies ( \pm SEM) of rats to balance on a beam before and after TBI with secondary hypoxemic insult. Before injury, rats were tested for their ability to balance for up to 60 seconds on a beam. Beginning 1 day after injury, beam-balance latencies were measured daily for 5 consecutive days. All injured groups had shorter latencies (indicating impairment) on day 1 after injury. Shown are saline (filled diamonds), AG (filled circles), and L-NIL (open triangles) treatments. ${ }^{*} P<0.05$ vs. sham (open squares; shams were not subjected to $\mathrm{CCl}$ or hypoxemia). There were no differences between groups treated with iNOS inhibitors vs. saline after TBI. 
left hemisphere were outlined by a blinded observer (M4; Imaging Research Inc., St. Catharine's, Ontario, Canada). Contusion and hemispheric areas were measured. Contusion volume was calculated and expressed as percentage of the noninjured hemisphere. In sections taken through the lesion in rats, CA 1 and CA3 neurons in dorsal hippocampus were counted in 6 fields $(\times 400)$. Only normal-appearing neurons (having a clearly defined cell body and nucleus) were counted (33). Cell counts were expressed as the mean number of surviving neurons per high-power field (HPF). To produce a robust functional deficit in mice (without hypoxemic insult) required an injury level that breached the hippocampus, precluding assessment of CA1 and CA3 neuron counts in mice.

Rat study protocol. Immediately after injury, coded unprimed Alzet pumps were implanted subcutaneously to deliver AG (Sigma Chemical Co., St. Louis, Missouri, USA; $180 \mathrm{mg} / \mathrm{kg}$ per day for 5 days) (41), LNIL (Alexis Corp., Laufelfingen, Switzerland; 60 $\mathrm{mg} / \mathrm{kg}$ per day for 1.5 days) (43-45), or saline vehicle (for 5 days). Therapies were assigned in a randomized and blinded fashion; all outcome parameters were assessed by investigators blinded to group. Rats $(n=$ 32) were injured to achieve a sample size of 10 per group, to survive 21 days. Six shams (with craniotomy but no hypoxemic insult) were also studied. Outcome assessments included beam-balance and beam-walking latencies (days 1-5), cognition (MWM, days 14-20), and neuropathology (day 21).

Mouse study protocol. Targeted disruption of the murine iNOS gene was used to generate $i \mathrm{NOS}^{-/-}$mice, as described previously (46). Knockout mice were backcrossed 4 times onto a C57BL/6J background. PCR of genomic DNA was used to confirm the genotype of $\mathrm{NOS}^{-/-}$and $i \mathrm{NOS}^{+/+}$mice in randomly selected animals (data not shown). Male $i \mathrm{NOS}^{-/-}$mice $(n=10)$ were compared with male wild-type mice $\left(\mathrm{iNOS}^{+/+}, n=\right.$ 11). Wire grip was assessed on days $1-5$ after injury, while MWM performance was assessed on days 14-20. Neuropathologic outcome was assessed on day 21. Because the role of iNOS in motor performance and spatial memory acquisition was not known, we also assessed uninjured mice ( $\mathrm{NOOS}^{+/+}$and $i \mathrm{NOS}^{-/-}$) using both MWM and motor tests. Therefore, there were 4 groups of mice tested in this study: $i \mathrm{NOS}^{-/-}$and $i \mathrm{NOS}^{+/+}$mice subjected to either CCI or no injury. Outcome was assessed by investigators blinded to group.

Statistics. Results of the motor and MWM tests were analyzed using 2-way ANOVA for repeated measures. Lesion volumes and hippocampal neuron counts were compared using ANOVA or Student's 2-tailed $t$ tests. Appropriate post hoc multiple comparison tests were applied. Data are presented as mean \pm SEM.

\section{Results}

iNOS $m R N A$ is increased after TBI in rats and mice. RT-PCR verified that iNOS mRNA is increased in brain of both rats and mice after TBI. The time course of iNOS

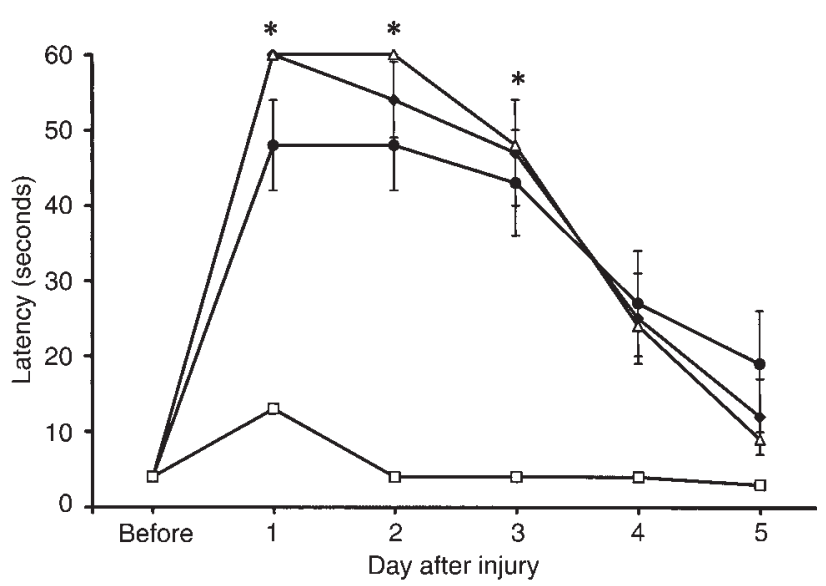

Figure 3

Mean latencies ( \pm SEM) of rats to traverse a beam before and after TBI with secondary hypoxemic insult. Before injury, rats were trained to traverse the beam within 5 seconds (Before). Beginning 1 day after injury, latencies were measured daily for 5 days. All injured groups had longer (impaired) latencies on days 1-3 after injury. Shown are saline (filled diamonds), AG (filled circles), and L-NIL (open triangles) treatments. ${ }^{*} P<0.05$ vs. sham (open squares; shams were not subjected to $\mathrm{CCl}$ or hypoxemia). There were no differences between groups treated with iNOS inhibitors vs. saline after TBI.

mRNA expression is shown in Figure 1, a and b. In rats, iNOS mRNA is increased at 2-72 hours in injured cortex (compared with uninjured) and at 2-6 hours in ipsilateral hippocampus. Maximal iNOS mRNA expression occurs at 6 hours. We were unable to detect iNOS PCR product in rat brain at either 30 or 60 minutes after TBI (data not shown). Compared with rats, brain iNOS mRNA expression in mice after TBI was delayed. In injured cortex from $i \mathrm{NOS}^{+/+}$mice, iNOS mRNA was not detected by RT-PCR until 24 hours after TBI, with increasing expression up to 72 hours. These data suggest that the temporal expression of iNOS is speciesdependent. Transcription of iNOS is more rapid in rats than in mice after TBI.

Rat functional and neuropathologic outcome. Two of 32 traumatized rats died (1 each in the vehicle- and AGtreated groups). These rats died on days 2 and 3 after injury. Physiologic parameters (body weight, arterial blood gas values, MABP, hematocrit, and blood glucose) in rats, both before and at 25 minutes after TBI, are shown in Table 1 . There was only 1 significant difference in any physiologic parameter between groups before TBI. $\mathrm{PaO}_{2}$ was lower in the L-NIL-treated rats before TBI (compared with vehicle and AG treatment). However, all rats in the study had a $\mathrm{PaO}_{2}$ over 110 $\mathrm{mmHg}$ before injury. At 25 minutes after injury, as expected, shams had higher $\mathrm{PaO}_{2}$ and MABP than did any of the injury groups (shams were not subjected to CCI or hypoxemia). Impact velocity did not differ between groups (data not shown).

All injured rats showed an equal decrement in motor function (measured with beam-balance and beam-walking tasks) compared with shams (Figures 2 and 3). Func- 


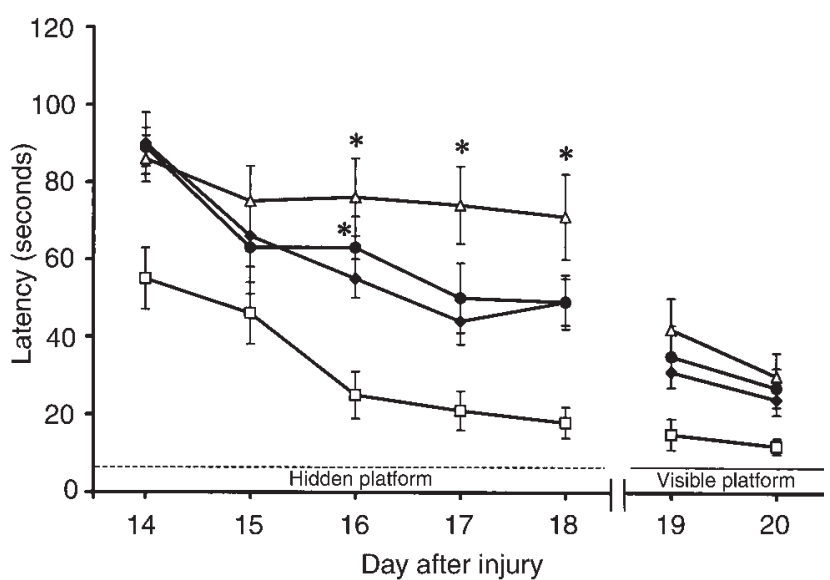

Figure 4

The effects ofTBI with secondary hypoxemic insult and treatment with iNOS inhibitors on MWM performance in rats. Mean latencies $( \pm$ SEM) to find a submerged (hidden) platform on days 14-18 after TBI. All injured groups had the longest (most impaired) latencies on day 14 after injury. However, rats treated with either of the iNOS inhibitors (AG or L-NIL) exhibited persistently higher latencies to find the platform on days 16,17 , and 18 after injury, compared with sham (open squares). Shown are saline (filled diamonds), AG (filled circles), and L-NIL (open triangles) treatments. ${ }^{*} P<0.05$ vs. sham. Improved performance on visible-platform testing (compared with hidden-platform testing) done on days 19-20 indicates that the deficits seen were not caused by visual impairment.

tion gradually improved over the 5-day test period. MWM latency on days 14-18 after TBI was significantly worse in all injured rats compared with shams (Figure 4). Members of all injured groups had a longer latency to find the hidden platform than did shams on day 14; however, the group treated with AG performed significantly worse than shams did on day 16 after TBI. Similarly, rats treated with L-NIL continued to have poor performance on days 16,17 , and 18 ( $P<0.05$ vs. shams). Latency improved during visible-platform testing for all groups on days 19-20, indicating that visual impairment was not the reason for impaired MWM performance after injury. There were no differences $(P>0.05)$ in swim speed $(\mathrm{cm} / \mathrm{s})$ between the vehicle $(33.1 \pm 3.0)$, AG $(35.1 \pm$ 3.4), L-NIL (29.4 \pm 2.2$)$, and sham (30.9 \pm 1.3$)$ groups.

We found no difference in contusion volume (percent of the noninjured hemisphere) in groups treated with AG (12.79 \pm 1.52$)$, L-NIL (11.90 \pm 0.87$)$, and saline (11.64 \pm 1.62 ). The level of injury used in this model causes a significant decrease in CA3 hippocampal neuron counts compared with sham (Figure 5; ref. 33). Rats treated with AG or L-NIL had a further reduction in CA3 hippocampal neuron count $(P<0.05$ vs. either sham or TBI). Consistent with our prior report (33), the injury in this model caused only a modest decrease in CA1 hippocampal neuron counts compared with sham (Figure 6). However, loss of CA1 neurons was exacerbated by treatment with either of the iNOS inhibitors $(P<0.05$ vs. sham for both); rats that received AG had lower CA1 neuron counts than did saline-treated controls that were also subjected to injury.
Mouse functional and neuropathologic outcome. Body weight did not differ between the $i \mathrm{NOS}^{+/+}$and $i \mathrm{NOS}^{-/-}$ groups (27.6 \pm 0.2 and $26.8 \pm 1.2 \mathrm{~g}$, respectively). One of the 21 injured mice (in the $i \mathrm{NOS}^{-/}$group) died. In uninjured groups, the performance of $i \mathrm{NOS}^{-/-}$mice did not differ from $i \mathrm{NOS}^{+/+}$mice in either wire grip or MWM (Figures 7 and 8). There were no differences between $\mathrm{NOS}^{+/+}$and $\mathrm{iNOS}^{-/-}$groups in brain temperature $\left(37.24 \pm 0.05\right.$ and $37.10 \pm 0.07^{\circ} \mathrm{C}$, respectively) or impact velocity $(6.03 \pm 0.04$ and $6.04 \pm 0.03 \mathrm{~m} / \mathrm{s}$, respectively). Wire-grip scores were equally impaired for both $\mathrm{NOS}^{+/+}$and $i \mathrm{NOS}^{-/-}$mice after CCI $(P<0.05$ vs. uninjured; Figure 7). MWM performance of injured $\mathrm{NOOS}^{+/+}$and $i \mathrm{NOS}^{-/-}$mice was significantly impaired after TBI compared with both uninjured groups. However, latencies to find the hidden platform in the MWM tests were greater in $i \mathrm{NOS}^{-/-}$mice than in $i \mathrm{NOS}^{+/+}$mice on days 15 and 18 after injury $(P$ $<0.05)$, indicating impaired performance in $i \mathrm{NOS}^{-/-}$ mice (Figure 8). Visible-platform performance was better than hidden-platform performance in all groups, indicating that the decrement in performance in $i \mathrm{NOS}^{-/-}$mice (vs. $i \mathrm{NOS}^{+/+}$) after TBI was not due solely to impaired vision. Swim speeds $(\mathrm{cm} / \mathrm{s})$ in the injured $i \mathrm{NOS}^{-/-}$group $(10.4 \pm 2.4)$ were slower $(P<$ $0.05)$ than in the injured $i \mathrm{NOS}^{+/+}(17.5 \pm 1.4)$, uninjured $i \mathrm{NOS}^{-/-}(22.6 \pm 2.2)$, and uninjured $i \mathrm{NOS}^{+/+}(23.7$ \pm 1.1 ) groups. Contusion volume (percent of noninjured hemisphere) did not differ between injured groups $\left(\mathrm{iNOS}^{+/+}, 5.51 \pm 0.83 ; \mathrm{NOS}^{-/-}, 4.93 \pm 0.59\right)$.

\section{Discussion}

An endogenous beneficial effect of iNOS is shown in experimental TBI. This effect translated into significant worsening of functional endpoints in 2 species when iNOS was inhibited or lacking. Although the mechanisms producing this effect were not determined, this is, to our knowledge, the first study that

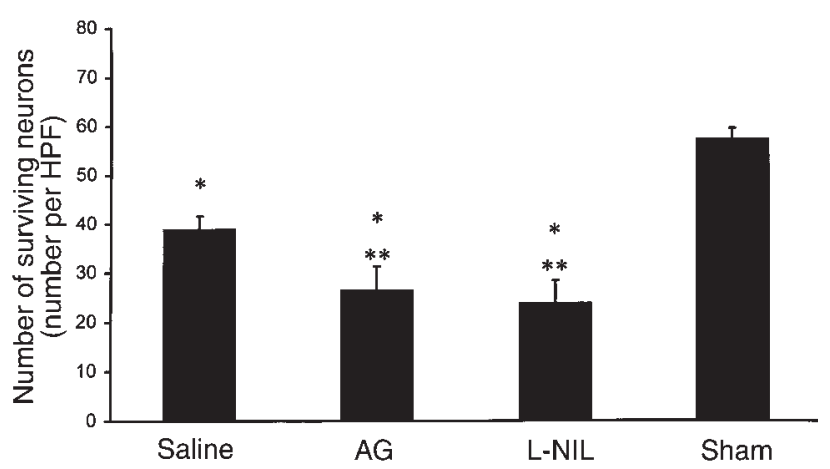

Figure 5

Number of surviving CA3 hippocampal neurons per HPF $(\times 400) \pm$ SEM at 21 days after TBI with secondary hypoxemic insult in rats treated with saline, AG, or L-NIL, and in shams. The number of surviving CA3 hippocampal neurons was reduced by TBI $\left({ }^{*} P<0.05\right.$ for saline vs. sham). Treatment with either of the iNOS inhibitors further reduced CA3 hippocampal neuron survival (AG and L-NIL both $P<$ 0.05 vs. ${ }^{*}$ sham or ${ }^{*}$ saline). 


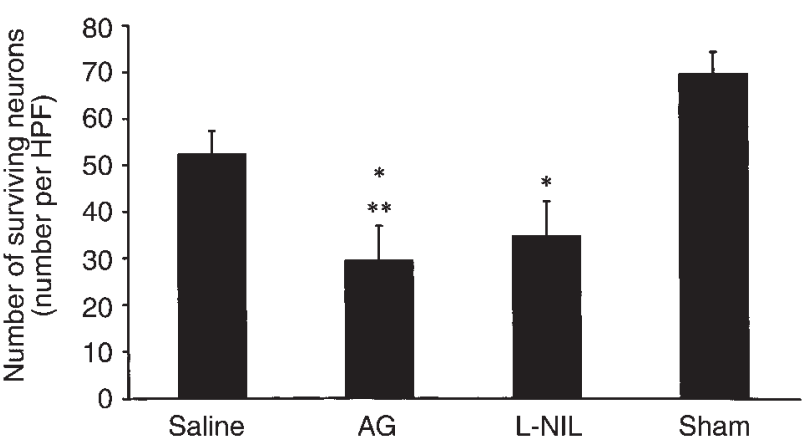

Figure 6

Number of surviving CA1 hippocampal neurons per HPF $(\times 400) \pm$ SEM at 21 days after TBI with secondary hypoxemic insult in rats treated with saline, AG, or L-NIL, and in shams. Treatment with either of the iNOS inhibitors reduced CA1 hippocampal neuron survival ( ${ }^{*} \mathrm{AG}$ and L-NIL both $P<0.05$ vs. sham). Rats treated with AG exhibited reduced $C A 1$ neuron survival vs. saline-treated rats after TBI $\left({ }^{*} P<0.05\right)$.

characterizes the long-term effect of treatment with iNOS inhibitors, or the use of mice deficient in iNOS, on functional outcome in a TBI model.

Our studies suggest that uninjured $\mathrm{NOS}^{-/-}$mice perform normally in motor and spatial memory acquisition tasks compared with wild-type mice. This argues against an essential role for iNOS in the events involved in completing these behavioral tasks, as was seen for eNOS in long-term potentiation (46-48), and argues strongly against a nonspecific functional deficit in our mutant mice (49).

The finding that iNOS can have beneficial effects in CNS disease has also been reported in a murine model of lymphocytic choriomeningitis (18). Expression of iNOS in infiltrating inflammatory cells prompted the assumption that iNOS-derived NO contributes to secondary damage (18). However, treatment with AG exacerbated neurologic injury and death. We previously reported upregulation of iNOS in infiltrating leukocytes and vasculature at 24-48 hours after TBI in rats (26). Our results in TBI are similar to recent reports in murine EAE. Two separate laboratories (31, 32) have reported worse outcomes in EAE models in $i \mathrm{NOS}^{-/-}$mice than in $i \mathrm{NOS}^{+/+}$mice. In both studies, the disease was earlier in onset and/or more aggressive in iNOS ${ }^{-1-}$ mice.

Unlike our findings in rats, we were unable to show exacerbation of hippocampal neuron damage at 21 days after TBI in mice. This may relate to the fact that in coronal brain sections taken through the injury in our mouse model, there is nearly complete hippocampal neuron loss. Alternatively, because the substrates for the functional deficits have yet to be determined in experimental TBI, the endogenous beneficial effect of iNOS on functional outcome could be mediated by mechanisms other than hippocampal neuron loss.

Our studies indicate that the inhibition of iNOS produces different effects in experimental TBI than those seen in models of focal cerebral ischemia, despite the use of identical species $(14,15,50)$. Cockroft et al. (29) reported reductions in infarct volume 24 hours after temporary focal cerebral ischemia in rats given AG (320 $\mathrm{mg} / \mathrm{kg}$ ) 15 minutes after the onset of ischemia. Iadecola et al. (28) reported a 33\% reduction in infarct volume (compared with vehicle treatment) using a 3 -day treatment regimen of AG $(100 \mathrm{mg} / \mathrm{kg}$ administered twice daily), beginning 24 hours after middle cerebral artery occlusion in spontaneously hypertensive rats. Infarct volume was assessed 4 days after occlusion. A $26 \%$ reduction in infarct volume at 4 days (compared with vehicle treatment) was also seen in rats subjected to focal cerebral ischemia and treated with this AG regimen, which inhibited brain iNOS activity $(28,30)$. We based our dosing for this study on that work. Finally, Iadecola et al. (15), reported an improvement in neurologic deficits and infarct volume 96 hours after focal ischemia in $\mathrm{NNOS}^{-/-}$ mice. Although L-NIL is a more selective inhibitor of NOS than is AG $(43,51)$, our report is the first to use this inhibitor in a model of brain injury.

There are differences between our study and studies by others of inhibition or deletion of iNOS in models of focal cerebral ischemia and FP-TBI. In our study, animals were serially evaluated for functional outcome over long periods of time, and histology was assessed at a delayed time (3 weeks) after injury. In contrast, studies of inhibition or deletion of iNOS in models of focal cerebral ischemia have invariably involved quicker follow-up (24-96 hours). These differences might be magnified by both of the sustained treatment paradigms in the rat experiments and in the $\mathrm{NOOS}^{-/-}$mice, where the beneficial effects of iNOS-derived NO are absent for the duration of the study. Marked temporal dependence of the effect of AG treatment has also been reported in EAE (52). Treatment with AG before onset

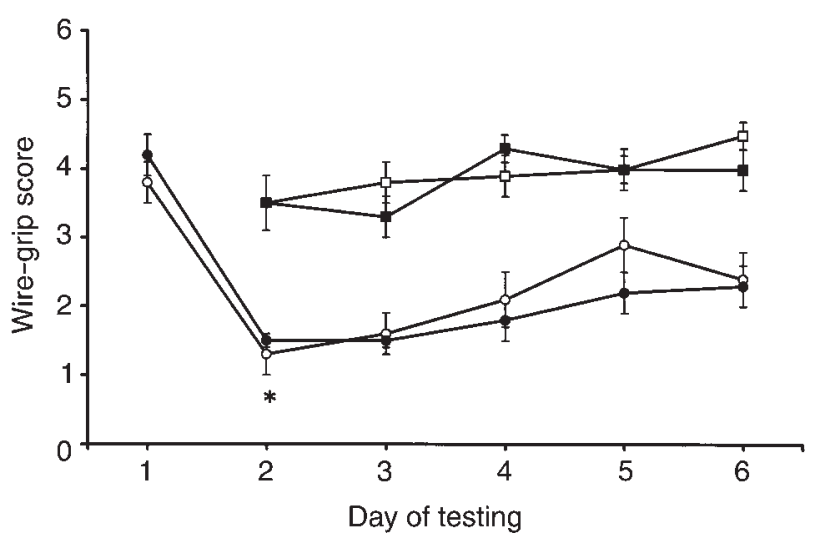

\section{Figure 7}

Assessment of motor function in mice using wire-grip scores (mean $\pm \mathrm{SEM}$ ). Uninjured $\mathrm{NNOS}^{+/+}$(open squares) and $\mathrm{NOS}^{-/-}$(filled squares) mice performed equally well in this task, as assessed for 5 days. In 2 separate groups of mice, both NOS $^{+/+}$(open circles) and iNOS $^{-1-}$ (filled circles) exhibited reduced scores (deficits) in this task after injury (day 1 shows preinjury score; day 2 of testing represents the first postinjury day). ${ }^{*} P<0.05$ vs. preinjury scores. There were no differences between $i \mathrm{NOS}^{+/+}$and $i \mathrm{NOS}^{-/-}$groups after injury. 
of symptoms was beneficial, while treatment after the onset of disease worsened outcome. Our findings are similar to recent work investigating the role of TNF- $\alpha$ in TBI. Soon after injury in rats or mice, TNF- $\alpha$ is detrimental $(53,54)$. However, TNF- $\alpha^{-/}$mice exhibit worse outcomes than do TNF- $\alpha^{+/+}$mice after TBI when outcome assessment is delayed beyond 1 week, supporting an endogenous beneficial effect (54). Consistent with a putative detrimental effect of iNOS soon after brain injury, but a beneficial long-term effect, Wada et al. (55) and Stoffel et al. (56) have reported beneficial effects on neuron survival and edema (respectively) during the initial 72 hours in rats treated with AG immediately after cortical FP or freeze injury, respectively.

Beneficial effects in TBI may be conferred by iNOS through a variety of mechanisms. Excitotoxicity mediates secondary damage after TBI (57). After $N$-methyl$\mathrm{D}$-aspartate (NMDA) receptor activation, $\mathrm{NO}$ can be either neuroprotective or neurodestructive, depending on the ambient redox milieu (16). NO-mediated $S$ nitrosylation of thiol groups on the NMDA receptor's redox modulatory site downregulates NMDA receptor activity, attenuating excitotoxicity (16). iNOS may also inhibit apoptosis (58-61). This could involve $S$-nitrosylation of caspases (62) or cGMP-mediated inhibition of apoptosis signaling $(58,60,61)$. NO delays death of trophic factor-deprived PC12 cells by a cGMP-mediated effect, and prolongs survival of embryonic motor neurons $(60,61)$.

Beneficial effects of iNOS in TBI could be related to inflammatory mechanisms. Protective effects of iNOS in EAE models may be mediated by an NO-mediated shift in the T-helper (Th) lymphocyte cytokine balance from a Th1 (proinflammatory) to a Th2 (anti-inflammatory) profile $(31,32)$. By inhibiting IL-12 synthesis, iNOS blocks the development of Th1 cytokine-producing cells (63). A marked Th1-type cytokine response develops in $\mathrm{NNOS}^{-/-}$mice in response to chronic inflammatory stimuli (64). Also, $i \mathrm{NOS}^{-/-}$mice have shown enhanced leukocyte-endothelium interactions in response to endotoxin (65). (Leukocytes accumulate after TBI; ref. 66.)

iNOS may also play a role in signaling the neurotrophic response after TBI. A $60 \%$ reduction in IL-6 and G-CSF mRNA levels and NF- $\mathrm{KB}$ activation in liver and lung is seen after hemorrhagic shock in $\mathrm{NOS}^{-/-}$ mice compared with $i \mathrm{NOS}^{+/+}$mice (67). Inhibition of cytokines downregulates the production of nerve growth factor (NGF) in contused brain (9). Th2derived cytokines stimulate NGF synthesis, while Th1-derived cytokines inhibit NGF synthesis, supporting a possible link between delayed NO production and NGF (68-70). However, our preliminary studies do not support this mechanism to explain the observed difference in outcome. A 3-fold increase in NGF in cortical brain homogenates taken 24 hours after CCI was observed in both $\mathrm{NOS}^{+/+}$and $\mathrm{iNOS}^{-/-}$ mice (data not shown).

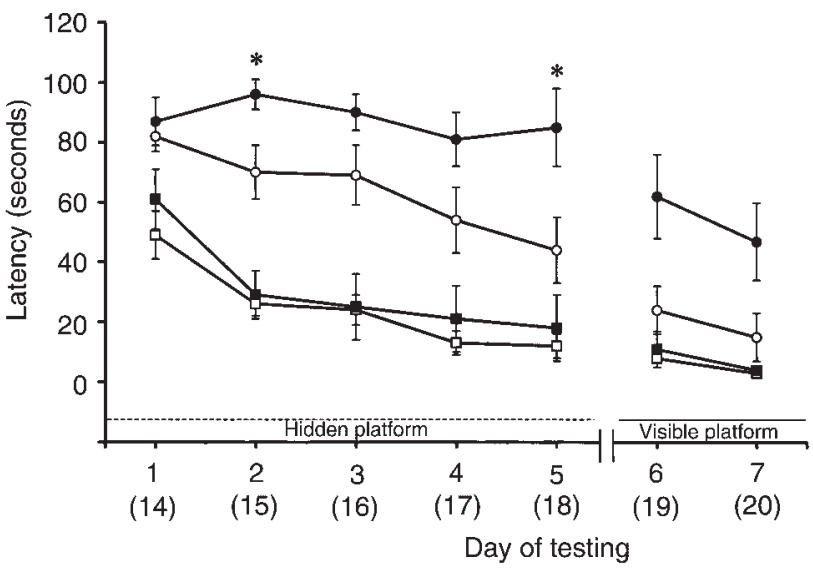

\section{Figure 8}

Spatial memory performance using an MWM paradigm in mice. Mean latencies ( \pm SEM) to find a submerged (hidden) platform on days 14-18 after TBI. Uninjured NOS $^{+/+}$(open squares) and $\mathrm{NOS}^{-/-}$ (filled squares) mice performed equally well on this task, as assessed for 5 days. After injury, both iNOS ${ }^{+/+}$(open circles) and iNOS ${ }^{-/-}$ (filled circles) mice showed impaired performance, as assessed for 5 days (vs. either uninjured group). After TBI, iNOS ${ }^{-1-}$ mice showed markedly impaired performance $\left({ }^{*} P<0.05 \mathrm{vs}\right.$. injured $i \mathrm{NOS}^{+/+}$mice on days 15 and 18$)$. Improved performance on visible-platform testing (days 19-20) indicates that the deficits seen were not due to visual impairment.

Finally, hypoperfusion develops in the contusion for 8-24 hours after experimental TBI, and iNOSderived NO may improve perfusion in penumbral regions $(19,71-73)$.

There are several limitations to this study. In mice, we cannot rule out unrecognized physiologic differences between groups. Also, we did not perform doseresponse studies with AG and L-NIL, nor did we confirm the duration or extent of inhibition of brain iNOS activity that each produces. This may be important for dosing of L-NIL, because it has not been studied in ischemia or TBI. However, our doses of L-NIL were similar to those used to attenuate systemic nitrite production in rats after endotoxin administration (45). Although the blood-brain barrier (BBB) penetration of $\mathrm{L}-\mathrm{NIL}$ is uncertain, the $\mathrm{BBB}$ is permeable to albumin for at least 8 hours after CCI (74).

An endogenous beneficial role for iNOS is shown after experimental TBI in both rats and mice. Although the mechanism of this effect remains to be determined, our findings mirror those seen in models of subacute or chronic inflammation within and outside the CNS, and suggest a beneficial role for iNOS on long-term outcome after TBI.

\section{Acknowledgments}

This work was supported in part by grants from the American Heart Association, Pennsylvania Affiliate (to P.M. Kochanek and S.C. Watkins); the Charles Schertz Fellowship Award from the Department of Anesthesiology and Critical Care Medicine, University of Pittsburgh (to E.H. Sinz); and National Institutes of Health 
grants NS-30318 (to D.W. Marion, P.M. Kochanek, C.E. Dixon, and S.T. DeKosky), GM-44100 (to T.R. Billiar), and NS38620 (to R.S.B. Clark). We thank Marci Provins for typing the manuscript, and Bradley Stezoski for preparation of the figures.

1. Lassmann, H. 1997. Basic mechanisms of brain inflammation. J. Neural Transm. Suppl. 50:183-190.

2. McGeer, P.L., and McGeer, E.G. 1995. The inflammatory response system of brain: implications for therapy of Alzheimer and other neurodegenerative diseases. Brain Res. Brain Res. Rev. 21:195-218.

3. Pfister, H.W., and Scheld, W. 1997. Brain injury in bacterial meningitis: therapeutic implications. Curr. Opin. Neurol. 10:254-259.

4. Feuerstein, G.Z., Wang, X., and Barone, F.C. 1997. Inflammatory gene expression in cerebral ischemia and trauma. Potential new therapeutic targets. Ann. NY Acad. Sci. 825:179-193.

5. Hallenbeck, J.M. 1996. Significance of the inflammatory response in brain ischemia. Acta Neurochir. Suppl. 66:27-31.

6. Mattson, M.P., and Scheff, S.W. 1994. Endogenous neuroprotection factors and traumatic brain injury: mechanisms of action and implications for therapy. J. Neurotrauma. 11:3-33.

7. Bruce, A.J., et al. 1996. Altered neuronal and microglial responses to excitotoxic and ischemic brain injury in mice lacking TNF receptors. Nat. Med. 2:788-794.

8. Cheng, B., Christakos, S., and Mattson, M.P. 1994. Tumor necrosis factors protect neurons against metabolic-excitotoxic insults and promote maintenance of calcium homeostasis. Neuron. 12:139-153.

9. DeKosky, S.T., et al. 1996. Interleukin-1 receptor antagonist suppresses neurotrophin response in injured rat brain. Ann. Neurol. 39:123-127.

10. Mattson, M.P., Goodman, Y., Luo, H., Fu, W., and Furukawa, K. 1997. Activation of NF-kappaB protects hippocampal neurons against oxidative stress-induced apoptosis: evidence for induction of manganese superoxide dismutase and suppression of peroxynitrite production and protein tyrosine nitration. J. Neurosci. Res. 49:681-697.

11. Brown, G.C. 1997. Nitric oxide inhibition of cytochrome oxidase and mitochondrial respiration: implications for inflammatory, neurodegenerative and ischaemic pathologies. Mol. Cell. Biochem. 174:189-192.

12. Holscher, C. 1997. Nitric oxide, the enigmatic neuronal messenger: its role in synaptic plasticity. Trends Neurosci. 20:298-303.

13. Bredt, D.S., Hwang, P.M., and Snyder, S.H. 1990. Localization of nitric oxide synthase indicating a neural role for nitric oxide. Nature. 347:768-770.

14. Iadecola, C., Zhang, F., Xu, S., Casey, R., and Ross, M.E. 1995. Inducible nitric oxide synthase gene expression in brain following cerebral ischemia. J. Cereb. Blood Flow Metab. 15:378-384.

15. Iadecola, C., Zhang, F., Casey, R., Nagayama, M., and Ross, M.E. 1997. Delayed reduction of ischemic brain injury and neurological deficits in mice lacking the inducible nitric oxide synthase gene. J. Neurosci. 17:9157-9164.

16. Lipton, S.A., et al. 1993. A redox-based mechanism for the neuroprotective and neurodestructive effects of nitric oxide and related nitroso-compounds. Nature. 364:626-632.

17. Ding, M., Wong, J.L., Rogers, N.E., Ignarro, L.J., and Voskuhl, R.R. 1997. Gender differences of inducible nitric oxide production in SJL/J mice with experimental autoimmune encephalomyelitis. J. Neuroimmunol. 77:99-106.

18. Campbell, I.L. 1996. Exacerbation of lymphocytic choriomeningitis in mice treated with the inducible nitric oxide synthase inhibitor aminoguanidine. J. Neuroimmunol. 71:31-36.

19. DeWitt, D.S., et al. 1997. L-arginine and superoxide dismutase prevent or reverse cerebral hypoperfusion after fluid-percussion traumatic brain injury. J. Neurotrauma. 14:223-233.

20. Huang, Z., et al. 1996. Enlarged infarcts in endothelial nitric oxide synthase knockout mice are attenuated by nitro-L-arginine. J. Cereb. Blood Flow Metab. 16:981-998.

21. Huang, Z., et al. 1994. Effects of cerebral ischemia in mice deficient in neuronal nitric oxide synthase. Science. 265:1883-1885.

22. Schulz, J.B., et al. 1995. Blockade of neuronal nitric oxide synthase protects against excitotoxicity in vivo. J. Neurosci. 15:8419-8429.

23. Yoshida, T., Limmroth, V., Irikura, K., and Moskowitz, M.A. 1994. The NOS inhibitor, 7-nitroindazole, decreases focal infarct volume but not the response to topical acetylcholine in pial vessels. J. Cereb. Blood Flow Metab. 14:924-929.

24. Billiar, T.R. 1995. Nitric oxide. Novel biology with clinical relevance. Ann Surg. 221:339-349.

25. Taylor, B.S., et al. 1998. Multiple NF-kappaB enhancer elements regulate cytokine induction of the human inducible nitric oxide synthase gene. J. Biol. Chem. 273:15148-15156.

26. Clark, R.S., et al. 1996. Inducible nitric oxide synthase expression in cerebrovascular smooth muscle and neutrophils after traumatic brain injury n immature rats. Pediatr. Res. 39:784-790.

27. D’Ambrosio, R., Maris, D.O., Grady, M.S., Winn, H.R., and Janigro, D. 1998. Selective loss of hippocampal long-term potentiation, but not depression, following fluid percussion injury. Brain Res. 786:64-79.

28. Iadecola, C., Zhang, F., and Xu, X. 1995. Inhibition of nitric oxide synthase ameliorates cerebral ischemic damage. Am. J. Physiol. 268:R286-R292.

29. Cockroft, K.M., et al. 1996. Cerebroprotective effects of aminoguanidine in a rodent model of stroke. Stroke. 27:1393-1398.

30. Zhang, F., Casey, R.M., Ross, M.E., and Iadecola, C. 1996. Aminoguanidine ameliorates and L-arginine worsens brain damage from intraluminal middle cerebral artery occlusion. Stroke. 27:317-323.

31. Fenyk-Melody, J.E., et al. 1998. Experimental autoimmune encephalomyelitis is exacerbated in mice lacking the nitric oxide synthase 2 gene. J. Immunol. 160:2940-2946.

32. Sahrbacher, U.C., et al. 1998. Mice with an inactivation of the inducible nitric oxide synthase gene are susceptible to experimental autoimmune encephalomyelitis. Eur. J. Immunol. 28:1332-1338.

33. Clark, R.S.B., et al. 1997. Early neuropathologic effects of mild or moderate hypoxemia after controlled cortical impact injury in rats. J. Neurotrauma. 14:179-189.

34. Dixon, C.E., Clifton, G.L., Lighthall, J.W., Yaghamai, A.A., and Hayes, R.L. 1991. A controlled cortical impact model of traumatic brain injury in the rat. J. Neurosci. Methods. 39:253-262.

35. Kochanek, P.M., et al. 1995. Severe controlled cortical impact in rats: assessment of cerebral edema, blood flow, and contusion volume. J. Neurotrauma. 12:1015-1025.

36. Clark, R.S.B., et al. 1997. Apoptosis-suppressor gene $b c l-2$ expression after traumatic brain injury in rats. J. Neurosci. 17:9172-9182.

37. Smith, D.H., et al. 1995. A model of parasagittal controlled cortical impact in the mouse: cognitive and histopathologic effects. J. Neurotrauma. 12:169-178.

38. Whalen, M.J., et al. 1999. Effect of traumatic brain injury in mice deficient in intercellular adhesion molecule-1: assessment of histopathologic and functional outcome. J. Neurotrauma. 16:299-309.

39. Carcillo, J.A., Parise, A., and Romkes-Sparks, M. 1994. Comparison of the enzyme-linked oligonucleotide sorbent assay to the ${ }^{32} \mathrm{P}$-labeled PCR/Southern blotting technique in quantitative analysis of human and rat mRNA. PCR Methods Appl. 3:292-297.

40. Dixon, C.E., et al. 1987. A fluid percussion model of experimental brain injury in the rat. J. Neurosurg. 67:110-119.

41. Feeney, D.M., Gonzalez, A., and Law, W.A. 1982. Amphetamine, haloperiodol, and experience interact to affect rate of recovery after motor cortex injury. Science. 217:855-857.

42. Hall, E.D., Yonkers, P.A., McCall, J.M., and Braughler, J.M. 1988. Effects of the 21-aminosteroid U74006F on experimental head injury in mice. J. Neurosurg. 68:456-461.

43. Southan, G.J., and Szabo, C. 1996. Selective pharmacological inhibition of distinct nitric oxide synthase isoforms. Biochem. Pharmacol. 51:383-394.

44. Moore, W.M., et al. 1994. L-N6-(1-iminoethyl) lysine: a selective inhibitor of inducible nitric oxide synthase. J. Med. Chem. 37:3886-3888.

45. Wray, G.M., Millar, C.G., Hinds, C.J., and Thiemermann, C. 1998. Selective inhibition of the activity of inducible nitric oxide synthase prevents the circulatory failure, but not the organ injury/dysfunction, caused by endotoxin. Shock. 9:329-335.

46. Dinerman, J.L., Dawson, T.M., Schell, M.J., Snowman, A., and Snyder, S.H. 1994. Endothelial nitric oxide synthase localized to hippocampal pyramidal cells: implications for synaptic plasticity. Proc. Natl. Acad. Sci. USA. 91:4214-4218.

47. Kantor, D.B., et al. 1996. A role for endothelial NO synthase in LTP revealed by adenovirus-mediated inhibition and rescue. Science. 274:1744-1748

48. O'Dell, T.J., et al. 1994. Endothelial NOS and the blockade of LTP by NOS inhibitors in mice lacking neuronal NOS. Science. 265:542-546.

49. Banbury Conference on Genetic Background in Mice. 1997. Mutant mice and neuroscience: recommendation concerning genetic background. Neuron. 19:755-759.

50. Iadecola, C., Zhang, F., Casey, R., Clark, H.B., and Ross, M.E. 1996. Inducible nitric oxide synthase gene expression in vascular cells after transient focal cerebral ischemia. Stroke. 27:1373-1380.

51. Bryk, R., and Wolff, D.J. 1998. Mechanism of inducible nitric oxide synthase inactivation by aminoguanidine and L-N6-(1-iminoethyl) lysine. Biochemistry. 37:4844-4852.

52. Okuda, Y., Sakoda, S., Fujimura, H., and Yanagihara, T. 1998. Aminoguanidine, a selective inhibitor of the inducible nitric oxide synthase, has different effects of experimental allergic encephalomyelitis in the induction and progression phase. J. Neuroimmunol. 81:201-210.

53. Shohami, E., Bass, R., Wallach, D., Yamin, A., and Gallily, R. 1996. Inhibition of tumor necrosis factor alpha (TNF alpha) activity in rat brain is associated with cerebroprotection after closed head injury.J. Cereb. Blood Flow Metab. 16:378-384 
54. Scherbel, U., Raghupathi, R., Nakamura, M., Saatman, K., and McIntosh, T.K. 1997. Evaluation of neurobehavioral deficits in brain-injured tumor necrosis factor-deficient (TNF-/-) mice after experimental brain injury. I. Neurotrauma. 14:781

55. Wada, K., Chatzipanteli, K., Kraydieh, S., Busto, R., and Dietrich, W.D. 1998. Inducible nitric oxide synthase expression after traumatic brain injury and neuroprotection with aminoguanidine treatment in rats. New rosurgery. 43:1427-1436.

56. Stoffel, M., Rinecker, M., Plesnila, N., Eriskat, J, and Baethmann, A. 1999. Attenuation of secondary lesion growth of the brain after trauma by selective inhibition of the inducible no-synthase. Proceedings of the Eleventh International Symposium of Brain Oedema and Mechanisms of Cellular Injury. 62. (Abstr.)

57. McIntosh, T.K. 1993. Novel pharmacologic therapies in the treatment of experimental traumatic brain injury: a review. J. Neurotrauma. 10:215-261.

58. Kim, Y.M., Talanian, R.V., and Billiar, T.R. 1997. Nitric oxide inhibits apoptosis by preventing increases in caspase-3-like activity via two distinct mechanisms. J. Biol. Chem. 272:31138-31148.

59. Tzeng, E., et al. 1997. Adenoviral transfer of the inducible nitric oxide synthase gene blocks endothelial cell apoptosis. Surgery. 122:255-263.

60. Estévez, A.G., et al. 1998. Nitric oxide-dependent production of cGMP supports the survival of rat embryonic motor neurons cultured with brain-derived neurotrophic factor. J. Neurosci. 18:3708-3714.

61. Farinelli, S.E., Park, D.S., and Greene, L.A. 1996. Nitric oxide delays the death of trophic factor-deprived PC12 cells and sympathetic neurons by a cGMP-mediated mechanism. J. Neurosci. 16:2325-2334.

62. Yakovlev, A.G., et al. 1997. Activation of CPP32-like caspases contributes to neuronal apoptosis and neurological dysfunction after traumatic brain injury. J. Neurosci. 17:7415-7424.

63. MacLean, A., et al. 1998. Mice lacking inducible nitric-oxide synthase are more susceptible to herpes simples virus infection despite enhanced Th1 cell responses. J. Gen. Virol. 79:825-830.
64. Wei, X.-Q., et al. 1995. Altered immune responses in mice lacking inducible nitric oxide synthase. Nature. 375:408-411.

65 . Hickey, M.J., et al. 1997. Inducible nitric oxide synthase-deficient mice have enhanced leukocyte-endothelium interactions in endotoxemia. FASEB J. 11:955-964.

66. Clark, R.S.B., Schiding, J.K., Kaczorowski, S.L., Marion, D.W., and Kochanek, P.M. 1994. Neutrophil accumulation after traumatic brain injury in rats: comparison of weight-drop and controlled cortical impact models. J. Neurotrauma. 11:499-506.

67. Hierholzer, C., et al. 1998. Essential role of induced nitric oxide in the initiation of the inflammatory response after hemorrhagic shock. J. Exp. Med. 187:917-928.

68. Brodie, C. 1996. Differential effects of Th1 and Th2 derived cytokines on NGF synthesis by mouse astrocytes. FEBS Lett. 394:117-120.

69. Brodie, C., Goldreich, N., Haiman, T., and Kazimirsky, G. 1998. Functional IL-4 receptors on mouse astrocytes: IL-4 inhibits astrocyte activation and induced NGF secretion. J. Neuroimmunol. 81:20-30.

70. Awatsuji, H., et al. 1993. Interleukin-4 and -5 as modulators of nerve growth factor synthesis/secretion in astrocytes. J. Neurosci. 34:539-545.

71. Forbes, M.L., et al. 1997. Assessment of cerebral blood flow and CO2 reactivity after controlled cortical impact by perfusion magnetic resonance imaging using arterial spin labeling in rats. J. Cereb. Blood Flow Metab. 17:865-874.

72. Yamakami, I., and McIntosh, T.K. 1991. Alterations in regional cerebral blood flow following brain injury in the rat. J. Cereb. Blood Flow Metab. 11:655-660.

73. von Stuck, S.L., Lee, S.M., Hovda, D.A., and Becker, D.P. 1996. L-arginine increases cerebral blood flow following cortical contusion injury: implications regarding vulnerability. J. Neurotrauma. 13:618.

74. Whalen, M.J., Carlos, T.M., Kochanek, P.M., and Heineman, S. 1998. Blood-brain barrier permeability, neutrophil accumulation and vascular adhesion molecule expression after controlled cortical impact in rats: a preliminary study. Acta Neurochir. Suppl. 71:212-214. 